UDC 343.211

LBC 67.408.014

\title{
MEASURE OF SOCIAL DANGER OF THE ACT AS THE BASIS FOR INTERBRANCH AND BRANCH DIFFERENTIATION OF LEGAL LIABILITY ${ }^{1}$
}

\author{
Lyubov V. Lobanova \\ Volgograd State University, Volgograd, Russian Federation
}

\begin{abstract}
The article notes the efficiency of philosophical approach to the determination of the basis of "interbranch differentiation of legal liability", since it involves the clarification of the basis (criteria) for the division of this liability into types. The main objectives of the study lie in clarifying the given ground and determining the difference of the latter and the basis of differentiation of criminal liability, the achievement of which is important for understanding the meaning of the provisions of the criminal law relating to the concept of crimes and their categorization as well as for assessing the quality of the regulation of the relevant legal instructions.

The author substantiates the judgment about the impossibility of recognizing criterion for interbranch differentiation of legal liability of presence or absence of public danger in the act as it is inherent in all such offenses. At the same time the measure of the specified material property of the offense is noted. It is emphasized that "transformation" of a wrongdoing into a crime is conditioned by transition (jump) from one measure of social danger of an act to the other. The measure of social danger of an illegal act embodying qualitative and quantitative certainty of the class of offenses and should be recognized as a criterion for interbranch differentiation of legal liability.

The paper also shows that in order to differentiate criminal liability it is already crucial to distinguish the extent of the social danger of the types of crimes, rather than the classes of offenses, the parameters of which the legislator calls the nature and degree of public danger. It is concluded that the lack of consensus in the theory of criminal law on the grounds for differentiation of legal liability at different levels of such division is due to some terminological uncertainty of legal provisions.
\end{abstract}

Key words: classification of crimes; interbranch differentiation of liability; the measure of social risk; social danger of the act; the basis of differentiation; crime; wrongdoing; criminal liability.

УДК 343.211

ББК 67.408 .014

\section{МЕРНОСТЬ ОБЩЕСТВЕННОЙ ОПАСНОСТИ ДЕЯНИЯ КАК ОСНОВА МЕЖОТРАСЛЕВОЙ И ОТРАСЛЕВОЙ ДИФФЕРЕНЦИАЦИИ ЮРИДИЧЕСКОЙ ОТВЕТСТВЕННОСТИ ${ }^{1}$}

\author{
Любовь Валентиновна Лобанова \\ Волгоградский государственный университет, г. Волгоград, Российская Федерация
}


Автором обосновывается суждение о невозможности признания критерием межотраслевой дифференциации юридической ответственности наличия или отсутствия в деянии общественной опасности, ибо таковая присуща всем правонарушениям. В то же время отмечается мерность указанного материального свойства правонарушения. Подчеркивается, что «превращение» проступка в преступление обусловливается переходом (скачком) из одной меры общественной опасности деяния в другую. Меру общественной опасности противоправного деяния, воплощающую в себе качественно-количественную определенность класса правонарушений, и следует признавать критерием для межотраслевой дифференциации юридической ответственности.

В работе также показывается, что для дифференциации уголовной ответственности решающее значение уже приобретают различия в мере общественной опасности видов преступлений, а не классов правонарушений, параметры которой законодатель называет характером и степенью общественной опасности. Формулируется вывод о том, что отсутствие в теории уголовного права единодушия относительно оснований дифференциации правовой ответственности на различных уровнях такого деления обусловливается некоторой терминологической неопределенностью законоположений.

Ключевые слова: категоризация преступлений, межотраслевая дифференциация ответственности, мера общественной опасности, общественная опасность деяния, основание дифференциации, преступление, проступок, уголовная ответственность.

Понятие межотраслевой дифференциации ответственности в теории уголовного права имеет особое значение. Именно в ходе осуществления обозначаемого данным понятием законотворческого процесса должна быть проведена четкая разграничительная линия между деяниями, влекущими уголовную ответственность, то есть преступлениями, и деяниями, вызывающими к жизни юридические последствия иной отраслевой принадлежности, то есть проступками. Не случайно специалисты указанной отрасли правового знания стремятся подойти к определению данного понятия с философских позиций. Такой ракурс постижения сущности феномена межотраслевой дифференциации юридической ответственности обладает определенными преимуществами перед, скажем, толкованием изучаемого понятия исключительно с помощью приемов языкознания, в частности семантики, хотя и в том, и в другом случае приходится прибегать к интерпретации более общего понятия - «дифференциация». Например, в одном из словарей русского языка глагол «дифференцировать», от которого происходит слово «дифференциация», означает «различать отдельное, частное при рассмотрении, изучении чего-либо» $[12$, с. 62]. Нетрудно предположить, что подобная трактовка интересующего нас базового слова имеет ограниченную область применения. По-видимому, она рассчитана главным образом на познавательную деятельность. Этого недостатка лишено философское толкование термина «дифференци- ация». Здесь она определена как «выделение различающих моментов по единому принципу, исходя из одной отправной точки» [16, c. 231]. Помимо того, что данный подход к разъяснению характеризуемого понятия позволяет использовать результат толкования безотносительно к виду человеческой деятельности, он обладает еще одним достоинством: в число признаков определяемого понятия включено указание на осуществление разграничения, различения, исходя из одного принципа, критерия.

Благодаря отмеченному, истолкованный подобным образом термин «дифференциация» применим и к правотворческой деятельности, в рамках которой происходит дифференциация юридической ответственности. А использование его для обозначения последнего процесса заставляет правоведов искать ответ на вопрос о том, что именно служит той исходной точкой, которая определяет выбор законодателем параметров возможных правовых последствий для тех или иных форм человеческого поведения, негативно оцениваемых государством, а при обнаружении данного ответа позволяет оценивать последовательность и обоснованность предпринимаемых законодателем в этом направлении шагов.

По отношению к дифференциации юридической ответственности в целом соответствующий ориентир был намечен еще в 70-х гг. прошлого столетия В.И. Курляндским. Рассматривая такую дифференциацию как установление в законе различных видов 
юридической ответственности, автор отмечал, что она осуществляется с учетом «наиболее типичных свойств, характеризующих в обобщенном виде различные группы правонарушений» [6, с. 78]. Приведенная позиция находит поддержку у современных исследователей (см., например: [11, с. 12; 5, с. 6, 16, 41]). Однако вряд ли можно сказать, что ученые пришли к необходимому консенсусу относительно того, какие именно свойства преступления выделяют данное деяние среди других отрицательных поступков, заставляя уполномоченный орган представительной государственной власти наделять данное деяние статусом преступного.

Казалось бы, ответ на этот вопрос дал сам законодатель, который из всех официальных дефиниций видов правонарушений, выделяемых по отраслевому критерию, исключительно только в определении преступления включил указание на признак общественной опасности (ст. 14 УК РФ). Эпитетом «общественно опасное» не наделены, например, ни административное (ч. 1 ст. 2.1 КоАП РФ), ни налоговое правонарушение (ст. 106 ч. 1 Налогового кодекса РФ). На первый взгляд, это может служить весомым аргументом для обоснования позиции, согласно которой граница между преступными и непреступными деяниями определяется наличием общественной опасности у первых и отсутствием таковой у вторых [3, с. 135; 10, с. 149 и др.]. Как будто бы позволяет рассуждать подобным образом и содержание ст. 15 УК РФ, в которой на законодательном уровне объявлены в качестве критериев категоризации преступлений их характер и степень общественной опасности (ч. 1). Если качественный и количественный показатели общественной опасности деяния уже задействованы при проведении внутриотраслевых различий негативных юридических последствий содеянного, то что остается на долю межотраслевой дифференциации правовой ответственности? Разве не само наличие качества общественной опасности выделяет преступление среди других правонарушений и обусловливает наиболее репрессивный способ правового воздействия на такие деяния?

Однако не следует, на наш взгляд, поспешно давать на озвученные вопросы положительный ответ. При внимательном рас- смотрении приведенные положения оказываются не столь уж весомыми доводами.

Законодательное определение преступления не воспринимается в уголовно-правовой науке как безукоризненное. Некоторые ученые считают его неточным, особенно в части выражения материального, показывающего социальную природу преступного деяния признака. Подобная критика звучала еще на этапе формирования действующего уголовного закона $[2$, с. 4]. Справедливой она нам представляется и сегодня.

Утверждая последнее, мы вовсе не подвергаем сомнению тот факт, что различие между видами юридической ответственности, а равно между основаниями наступления (возложения) ответственности разного вида существенно. Однако напомним читателю суждение Аристотеля о недопустимости изолированного познания сущности, поскольку таковая непременно включена в классы однородных с ней сущностей $[1$, c. 45]. Именно однородными сущностями правовых явлений следует признать виды юридической ответственности, а соответственно и обособленные группы деяний, за которые данные варианты ответственности наступают. Общность юридических свойств всех этих деяний (противоправность, способность повлечь неблагоприятные последствия, характер и пределы которых определены нормами права, а реализация обеспечивается принудительной силой государства) предопределена единством их социальной природы. Последняя, в свою очередь, заключается в способности причинять существенный вред тем отношениям, которые важны для существования и нормального развития известной триады «личность, общество, государство» и одновременно служить основой для многократного повторения [подробнее об этом см.: 14, с. 103-110]. Для обозначения такой способности нет, пожалуй, более удачного термина, чем «общественная опасность». Он лучше, чем понятие «общественная вредность», которым иногда пытаются оперировать сторонники оспариваемой точки зрения [10, с. 149], объясняет готовность государства обеспечить посредством своих силовых структур реализацию юридической ответственности любого вида, а не только уголовной. Он также точнее отражает весь по- 
тенциал заложенной в правонарушении угрозы. Кроме того, термин «общественная опасность» в большей степени, чем термин «общественная вредность», способствует уяснению собирательности обозначаемого им свойства правонарушения, и, в частности, пониманию того факта, что вид противоправности, объем правовых негативных последствий зависит не только от реального причиненного вреда и ценности объекта, которому этот вред причинен, но и от целого ряда других признаков, характеризующих преступление или иное правонарушение, и позволяющих в своей совокупности судить о его действительной разрушительной силе, реализованной в конкретном случае лишь частично.

Вместе с тем выраженность обозначаемого термином «общественная опасность» свойства неодинакова для различных правонарушений, причем соответствующие различия могут быть не только количественными, но и качественными, обусловливающими переход из одной подсистемы в другую. Надо полагать, что именно такие качественно-количественные изменения общественной опасности деяний принимает во внимание законодатель, проводя границу между непреступным (подсистемой проступков) и преступным (подсистемой преступлений). Действительно, в криминализируемом деянии (если речь, конечно, не идет о правотворческой ошибке) интенсивность и оперативность негативного воздействия на социальные связи возрастает настолько, что неадекватность государственного реагирования на такие деяния с помощью иных средств, помимо уголовно-правовых, становится очевидной. Последние же отличаются не только уровнем репрессивности, жесткостью и объемом правоограничений, но и тем, что связаны с кардинальным изменением правового статуса лица, совершившего преступление. Ведь только реализация уголовной ответственности, а не какой-либо иной, способна породить состояние судимости.

В философской науке границы, за которыми количественные изменения переходят в качественные, принято именовать мерой [15, c. 211]. Подчеркивается при этом, что указанная категория выражает «органическое единство качественной и количественной определенности предмета или явления» [15, с. 211].
Отмечается также, что «каждому качественно своеобразному объекту присущи определенные количественные характеристики» $[15$, c. 211]. В то же время обращается внимание на подвижность данных характеристик и ограниченность подобной изменчивости определенными пределами [15, с. 211]. Признается в философии также и влияние качественных параметров на количественные. «В свою очередь, - развивают свою мысль о категории меры ученые, - изменение качества данного объекта ведет к изменению его количественных характеристик и меры» [15, с. 211].

На основе сказанного вполне логично, на наш взгляд, сделать вывод о том, что переход от проступка к преступлению обусловливается переходом от одной меры общественной опасности к другой. Не противоречит сказанному и суждение о том, что именно мерность категории «общественная опасность» является базой для использования данного понятия при описании критерия (основания) для межотраслевой дифференциации юридической ответственности. Искомой исходной точкой, отправным пунктом для дифференциации такого рода, вероятно, как раз и выступает мера общественной опасности признаваемого противоправным деяния, отражающая не только количественное, но и качественное своеобразие соответствующего вида поведения. Не совсем точным в этой связи следует считать утверждение, будто преступление отличается от проступков степенью общественной опасности [4, с. 119]. Подобная характеристика различия, претендующего служить критерием межотраслевой дифференциации юридической ответственности, позволяет акцентировать внимание исключительно на количественной разнице в проявлении социального свойства правонарушения, оставляя в тени качественную определенность преступлений, дающую возможность объединять последние в особый класс противоправных деяний. Гораздо ближе к истине суждения тех исследователей, которые усматривают некоторую собирательность в критерии отграничения преступлений от проступков. Так, В.В. Мальцев отмечал продуктивность выявления различия указанных видов противоправного поведения с помощью терминов «характер» и «степень» общественной опасности $[8$, 
c. 168]. И в самом деле слово «степень» хотя и имеет множество значений, в основном служит для выражения количественных различий сравниваемых предметов и явлений. Не случайно его обычные синонимы - «сравнительная величина», «сравнительное качество», «сравнительный размер» [13, с. 654]. О слове же «характер» этого сказать нельзя. Напротив, его употребление оправданно, когда требуется подчеркнуть «отличительное свойство, особенность чего-нибудь» $[13$, с. 732$]$, либо «совокупность определяющих свойств» [13, c. 732]. Следовательно, для того, чтобы показать не только количественную, но и качественную составляющую используемого для межотраслевой дифференциации юридической ответственности критерия, недостаточно оперировать понятием «степень». Столь же важно понятие «характер». Только выявление обоих названных параметров в совокупности дает возможность определить меру общественной опасности деяния, а следовательно и решить вопрос о соответствии социальных свойств последнего материальному признаку преступления. Но если в указанной паре категорий и следует отдать предпочтение одной из них, подчеркивая главное в основании межотраслевой дифференциации юридической ответственности, то это должна быть категория «характер общественной опасности деяния», поскольку лишь появление нового характера у рассматриваемого материального свойства правонарушения завершает процесс обретения им новой меры. Представляется, что именно это и имел в виду К. Маркс, напоминая законодателю о его долге «не превращать в преступление то, что имеет характер проступка» $[9$, с. 131].

Но согласуется ли сказанное с положениями упомянутой выше ст. 15 УК РФ, определяющей в качестве критериев подразделения преступлений на категории не что-нибудь, а характер и степень общественной опасности? Не противоречит ли оно также высказанному в теории уголовного права мнению, согласно которому основой для дифференциации уголовной ответственности также выступают обозначенные параметры общественной опасности преступления? Таким образом размышляет, например, Л.Л. Кругликов, добавляя при этом, что видное место в процессе данного рода дифференциации занимают типовые свойства личности преступника [5, с. 60].

Мы полагаем, что противоречие действительно можно заподозрить. Однако причиной его нам видится некоторая терминологическая неопределенность, заложенная в уголовном законе. Ведь говоря о том, что запрещенные Уголовным кодексом РФ деяния подразделяются на преступления небольшой тяжести, средней тяжести, тяжкие и особо тяжкие преступления по характеру и степени общественной опасности, законодатель не уточняет, о мере общественной опасности каких именно деяний в данном случае идет речь. В подобных условиях вполне можно поддаться заблуждению, что имеются в виду качественный и количественный параметры всего класса преступлений. Отсюда и отрицание некоторыми авторами возможности признать критерием градации уголовной ответственности характер общественной опасности преступления. Например, Т.А. Лесниевски-Костарева пришла к такому заключению в силу того, что указанный параметр общественной опасности лежит в основе установления уголовной ответственности [7, с. 45], а следовательно и ее отграничения от других видов юридической ответственности, то есть межотраслевой дифференциации последней.

Казалось бы, аргумент вполне состоятельный. У дифференциации юридической ответственности на виды (межотраслевая) и дифференциации одного и того же вида ответственности (уголовной), результатом которой выступают формы проявления и объем именно данного вида ответственности, не может быть одного и того же основания. Это должны быть критерии, лежащие в границах разных мер.

Но в том-то и дело, что, говоря о характере общественной опасности как о критерии категоризации преступлений, законодатель вовсе и не имеет в виду тот качественный параметр общественной опасности деяния, который является общим для всего класса преступлений и в то же время отграничивает их от правонарушений иной отраслевой принадлежности. Здесь он (характер общественной опасности) указывает на качественную определенность преступлений, объединяемых законодателем в один и тот же вид (убийство, 
изнасилование, грабеж, разбой и т. д.). Таким образом, каждый из видов преступлений имеет собственную меру общественной опасности, хотя и находящуюся в границах меры общественной опасности всего класса преступлений. По справедливому мнению Л.Л. Кругликова, понимаемый в этом смысле характер общественной опасности преступления зависит от всех признаков основного состава преступления [5, с. 61]. Таким образом можно утверждать, что в ст. 15 УК РФ законодатель, упоминая о характере общественной опасности, подразумевает качественный параметр общественной опасности вида преступлений. Общий для всех преступлений одного и того же вида уровень общественной опасности скрывается под термином «характер общественной опасности преступления» в работах тех исследователей, которые признают данный показатель критерием (основанием) дифференциации уголовной ответственности.

Соответственно и степень общественной опасности как критерий категоризации преступлений является подвижным параметром меры общественной опасности, присущей виду преступлений, а не всему их классу. Это означает, что для дифференциации уголовной ответственности, осуществляемой посредством деления преступлений на категории с установлением за последние различных уголовно-правовых последствий, имеют значение также внутривидовые различия преступлений, определяемые наличием (отсутствием) квалифицирующих и (или) привилегирующих признаков.

Учитывая, что категоризация преступлений, осуществленная законодателем, имеет принципиальное значение для решения многих уголовно-правовых вопросов при определении принципа назначения наказания по совокупности преступлений, выборе вида исправительного учреждения, освобождении от уголовной ответственности и т. д., отмеченная терминологическая неопределенность в обозначении критериев дифференциации уголовной ответственности представляется небезобидной. Не способствует также пониманию специфики преступного посягательства, его отграничению от других правонарушений и неточность, допущенная законодателем в де- финиции преступления, о которой шла речь в начале настоящей работы.

Преодоление подобных погрешностей законодательной техники могло бы содействовать лучшему пониманию правоприменителем смысла законоположений, касающихся общего понятия преступлений и их категоризации. В этой связи предлагается внести следующие изменения в УК РФ: 1) в ч. 1 ст. 14 УК РФ материальный признак преступления изложить таким образом: «обладающее высокой мерой общественной опасности»; 2) ч. 1 ст. 15 УК РФ сформулировать так: «С учетом характера и степени общественной опасности вида преступлений деяния, предусмотренные настоящим Кодексом, подразделяются...» (далее по тексту).

\section{ПРИМЕЧАНИЕ}

${ }^{1}$ Исследование выполнено при финансовой поддержке Российского фонда фундаментальных исследований, проект № 17-03-00720.

\section{СПИСОК ЛИТЕРАТУРЫ}

1. Аристотель. Сочинения : в 4 т. Т. 4 / гл. ред., вступ. ст. А. И. Доватур, Ф. Х. Кесседи. - М. : Мысль, 1983. $-830 \mathrm{c}$.

2. Благов, Е. В. Основания ответственности по советскому уголовному праву / Е. В. Благов // Проблемы теории юридических фактов. - Ярославль : Изд-во ЯрГУ, 1988. - С. 7.

3. Дурманов, Н. Д. Понятие преступления /Н. Д. Дурманов. -М. : Изд-во АНСССР, 1948. -315 с.

4. Ковалев, М. И. Понятие преступления в советском уголовном праве / М. И. Ковалев. - Свердловск : Изд-во Уральского ун-та, 1987. - 208 с.

5. Кругликов, Л. Л. Проблемы теории уголовного права : избр. ст., 2000-2009 гг. / Л. Л. Кругликов. - Ярославль : Изд-во ЯрГУ, 2010. -591 с.

6. Курляндский, В. И. Уголовная политика, дифференциации и индивидуализация уголовной ответственности / В. И. Курляндский // Основные направления борьбы с преступностью. - М. : Наука, 1975. - С. 77-95.

7. Лесниевски-Костарева, Т. А. Дифференциация уголовной ответственности. Теория и законодательная практика / Т. А. Лесниевски-Костарева. M. : HOPMA, 1998. - $296 \mathrm{c}$.

8. Мальцев, В. В. Общественно опасное поведение в уголовном праве / В. В. Мальцев. - М. : Юрлитформ, 2014. - 648 с. 
9. Маркс, К. Сочинения / К. Маркс, Ф. Энгельс. - 2-е изд. - М. : Гос. изд-во полит. лит., 1955. T. $1 .-698 \mathrm{c}$.

10. Марцев, А. И. Общественная вредность и опасность преступления / А. И. Марцев // Известия высших учебных заведений. Правоведение. - 2001. № 4 (237). - С. 148-155.

11. Мельникова, Ю. Б. Юридическая ответственность: сущность, понятие, дифференциация / Ю. Б. Мельникова // Дифференциация ответственности в уголовном праве и процессе. - Ярославль : Изд-во ЯрГУ, 1994. - С. 3-19.

12. Ожегов, С. И. Словарь русского языка. 70000 слов / С. И. Ожегов ; под ред. Н. Ю. Шведовой. - 23-е изд., испр. - М. : Рус. яз., 1990. - 917 с.

13. Толковый словарь Д. Н. Ушакова / Д. Н. Ушаков. - М. : Аделант, 2014. - 800 с.

14. Уголовное право. Общая часть. Преступление. Академический курс : в 10 т. Т. 5. Понятие преступления. Состав преступления / под ред. Н. А. Лопашенко. - М. : Юрлитинформ, 2016. -600 с.

15. Философский словарь / под ред. И. Т. Фролова. - 4-е изд. - М. : Политиздат, 1981. - 445 с.

16. Философский энциклопедический словарь / сост. Е. Ф. Губский, Г. В. Кораблева, В. А. Лутченко. - М. : ИНФРА-М, 1999. - 576 c.

\section{REFERENCES}

1. Aristotel. Sochineniya: v 4 t. T. 4 [Aristotle. Works: in 4 vols. Vol. 4]. Moscow, Mysl Publ., 1983. $830 \mathrm{p}$.

2. Blagov E.V. Osnovaniya otvetstvennosti po sovetskomu ugolovnomu pravu [Grounds for Responsibility under the Soviet Criminal Law]. Problemy teorii yuridicheskikh faktov [Problems of the Theory of Legal Facts]. Yaroslavl, YArGU Publ., 1988, p. 7.

3. Durmanov N.D. Ponyatie prestupleniya [The Concept of Crime]. Moscow, Izd-vo AN SSSR, 1948. $315 \mathrm{p}$.

4. Kovalev M.I. Ponyatie prestupleniya $v$ sovetskom ugolovnom prave [The Concept of Crime in Soviet Criminal Law]. Sverdlovsk, Izd-vo Uralskogo un-ta, 1987. 208 p.

5. Kruglikov L.L. Problemy teorii ugolovnogo prava: izbr. st., 2000-2009 gg. [Problems of the Theory of Criminal Law: Selected Articles, 2000-2009]. Yaroslavl, YArGU Publ., 2010. 591 p.
6. Kurlyandskiy V.I. Ugolovnaya politika, differentsiatsii i individualizatsiya ugolovnoy otvetstvennosti [Criminal Policy, Differentiation and Individualization of Criminal Responsibility]. Osnovnye napravleniya borby s prestupnostyu [The Main Directions of Crime Prevention]. Moscow, Nauka Publ., 1975, pp. 77-95.

7. Lesnievski-Kostareva T.A. Differentsiatsiya ugolovnoy otvetstvennosti. Teoriya $i$ zakonodatelnaya praktika [Differentiation of Criminal Responsibility. Theory and Legislative Practice]. Moscow, Norma Publ., 1998. 296 p.

8. Maltsev V.V. Obshchestvenno opasnoe povedenie v ugolovnom prave [Socially Dangerous Behaviour in the Criminal Law]. Moscow, Yurlitform Publ., 2014. 648 p.

9. Marks K., Engels F. Sochineniya [Writings]. Moscow, Gos. izd-vo polit. lit. Publ., 1955, vol. 1.698 p.

10. Martsev A.I. Obshchestvennaya vrednost i opasnost prestupleniya [Public Harm and Danger of Crime]. Izvestiya vysshikh uchebnykh zavedeniy. Pravovedenie, 2001, vol. 4(237), pp. 148-155.

11. Melnikova Yu.B. Yuridicheskaya otvetstvennost: sushchnost, ponyatie, differentsiatsiya [Legal Responsibility: Essence, Concept, Differentiation]. Differentsiatsiya otvetstvennosti v ugolovnom prave $i$ protsesse [Differentiation of Responsibility in the Criminal Law and in the Criminal Procedure]. Yaroslavl, YarGU Publ., 1994, pp. 3-19.

12. Ozhegov S.I. Slovar russkogo yazyka. 70000 slov [Dictionary of the Russian Language. 70,000 Words]. Moscow, Russkiy yazyk Publ., 1990. 917 p.

13. Tolkovyy slovar D.N. Ushakova [Explanatory Dictionary of D.N. Ushakov]. Moscow, Adelant Publ., 2014. 800 p.

14. Lopashenko N.A., ed. Ugolovnoe pravo. Obshchaya chast. Prestuplenie. Akademicheskiy kurs: v 10 t. T. 5. Ponyatie prestupleniya. Sostav prestupleniya [Criminal Law. General Part. Crime. Academic Course. In 10 vols. Vol. 5. The Concept of Crime. Corpus Delicti]. Moscow, Yurlitinform Publ., 2016. 600 p.

15. Frolov I.T., ed. Filosofskiy slovar [Philosophical Dictionary]. Moscow, Politizdat Publ., 1981. 445 p.

16. GubskiyE.F., Korableva G.V., Lutchenko V.A. Filosofskiy entsiklopedicheskiy slovar [Philosophical Encyclopedic Dictionary]. Moscow, Infra-M Publ., 1999. 576 p. 


\section{Information about the Author}

Lyubov V. Lobanova, Doctor of Juridical Sciences, Professor, Head of Department of Criminal Law, Volgograd State University, Prosp. Universitetsky, 100, 400062 Volgograd, Russian Federation, up@volsu.ru,lobanova@volsu.ru.

\section{Информация об авторе}

Любовь Валентиновна Лобанова, доктор юридических наук, профессор, заведующая кафедрой уголовного права, Волгоградский государственный университет, просп. Университетский, 100, 400062 г. Волгоград, Российская Федерация, up@volsu.ru, lobanova@volsu.ru. 